\title{
A Randomized Control Trial To Assess And Evaluate The Effectiveness Of Pelvic Rocking Exercises In Reducing Dysmenorrhea Among Girls Of Selected Colleges Of Nursing In New Delhi.
}

\author{
Anju Verma
}

\section{Introduction}

Menstruation is a normal physiological phenomenon for women indicating her capability for procreation. However this normal phenomenon is not an easy one. It is often associated with some degree of sufferings and embarrassment. The prevalence of menstrual disorders has been recorded as high as $87 \%{ }^{(1)}$. Among the menstrual disorders, dysmenorrhea is the most common one being reported in half of the women of child bearing age and of these $10 \%$ experience incapacitating pain for $1-3$ days, every month ${ }^{(2)}$. In $60-90 \%$ of adolescent girls in India, dysmenorrhea is a major cause for absenteeism from school or restriction of activities of daily living or social interaction ${ }^{(3)}$. Exercise today is an integral part of normal life for many women. It is clear that there are many health benefits for women who exercise regularly and in moderation. Exercise improves cardiovascular status, increases bone mineral content; improves dysmenorrhoea and premenstrual syndrome symptoms ${ }^{(4,5,6)}$. Dysmenorrhoea is by far the most common \& arguably the least understood \& addressed complaint.

A systematic review of studies in developing countries reported that $25 \%$ to $50 \%$ of adult women and $75 \%$ of adolescents experienced dysmenorrhoea and that participation in usual activities was adversely affected in $5 \%$ to $20 \%$ of these women ${ }^{(7)}$. In one study, $98 \%$ of adolescents used non-pharmacological methods such as heat, rest, or distraction with a perceived effectiveness of $40 \%$ or less. There is increasing evidence that exercising at home may help reduce the pain and discomfort felt during menstrual cycle. Exercise is an accessible and convenient form of pain relief for women with primary dysmenorrhea, or pain during periods ${ }^{(8)}$.

\section{Methodology}

Present study used the Quantitative experimental research approach: Two group pre-test post-test design. The conceptual framework used for the study was based on the supportive educative system of the Dorothea Orem. For the present study first survey was conducted on 390 students in Rufaida College of Nursing and Laxmi Bai Batra College of Nursing to find out study subjects. Out of 390 students surveyed, 130 were found to be fulfilling the inclusion criteria that is having moderate to unbearable dysmenorrhoea for three consecutive cycles, age between 17-27 years and not having pelvic pathology. 60 subjects were selected through systematic random sampling. 30 were assigned in experimental group and 30 in control group. Subjects in experimental group were from Rufaida college of Nursing, New Delhi and in control group were from Laxmi Bai Batra College of Nursing, New Delhi. Pilot study was conducted from November 2011 to Dec 2011,in Rufaida College of Nursing and Laxmi Bai Batra College of Nursing. Final study was conducted in Rufaida College of Nursing and Laxmi Bai Batra College of Nursing in New Delhi from December 2011 to February 2012. The tool used for the present study were Semi- structured questionnaire to assess the menstrual pattern, Structured questionnaire to assess the symptoms associated with dysmenorrhoea, Verbal Descriptor Scale to assess the intensity of pain during menstruation.

Semi- structured questionnaire consisted of two sections: Section A and Section B. Section A had items on sample characteristics such as age, religion, marital status, type of family and dietary pattern. Section B comprised of 14 open ended questions to assess the menstrual pattern.

Structured questionnaire comprised of 21 symptoms grouped under four areas, such as, gastrointestinal symptoms (GI), psychological symptoms (PS), elimination symptoms (ES), and other physical symptoms. Reliability of the structured questionnaire was established by KR-20 and was found to be 0.7 . Verbal Descriptor Scale for assessing pain during menstruation was standardized and its reliability was already established. Reliability of Pelvic Rocking Exercises was established by Inter-rater reliability method and was found to be 1 $(100 \%)$.

Ethical approval was taken from the Institutional Review Board Jamia Hamdard University, New Delhi. Written Informed consent was taken from the sample subjects. Confidentiality of information given by study subjects maintained. While carrying out the study, subjects were empowered with full autonomy to participate in the research and withdrawn. 
Procedure of the study:

Menstrual pattern and menstrual symptoms assessed by using questionnaire.Intensity of pain assessed during menstruation by using Verbal Descriptor Scale.Pelvic Rocking Exercises practiced from the last day of menstruation till the next menstruation starts. Exercises practiced for 20 minute daily, 5 times in a week. Again intensity of pain assessed by using Verbal Descriptor Scale.

\section{Results}

Table-1 Frequency and Percentage Distribution of the Population by their Demographic Characteristics.

\begin{tabular}{lcc} 
& $\mathbf{N}=\mathbf{3 9 0}$ & \\
\hline Sample Characteristics & Frequency & Percentage (\%) \\
\hline Age in years & 345 & 88.46 \\
$17-22$ & 35 & 8.97 \\
$23-27$ & 10 & 2.56 \\
28 and above & & \\
Religion & 136 & 34.87 \\
Hindu & 116 & 29.74 \\
Muslim & & \\
Marital status & 380 & 97.43 \\
Unmarried & 10 & 2.564 \\
Married & & \\
Family type & 65 & 16.66 \\
Joint & 325 & 83.33 \\
Nuclear & & \\
Dietary habit & 99 & 25.38 \\
Vegetarian & 291 & 74.61 \\
Non-vegetarian & & \\
\hline
\end{tabular}

Table-2 Frequency and Percentage Distribution of Population as per the Age of Menarche, Duration of their Menstrual Cycle and Duration of their Menstruation. $N=390$

\begin{tabular}{llll}
\hline S.No. & & Frequency & Percentage (\%) \\
\hline $\mathbf{1}$ & Age at menarche (in years ) & 57 & 14.615 \\
$\mathbf{1 . 1}$ & $10-12$ & 315 & 80.769 \\
$\mathbf{1 . 2}$ & $13-15$ & 18 & 4.615 \\
$\mathbf{1 . 3}$ & $16-17$ & & \\
$\mathbf{2}$ & Duration of menstrual cycle (in days) & 3 & 0.769 \\
$\mathbf{2 . 1}$ & $<20$ & 53 & 13.589 \\
$\mathbf{2 . 2}$ & $20-25$ & 285 & 73.076 \\
$\mathbf{2 . 3}$ & $26-31$ & 43 & 11.025 \\
$\mathbf{2 . 4}$ & $32-42$ & 6 & 1.538 \\
$\mathbf{2 . 5}$ & $>42$ & & \\
$\mathbf{3}$ & Duration of menstrual flow (in days) & 12 & 3.0769 \\
$\mathbf{3 . 1}$ & $1-2$ & 303 & 77.692 \\
$\mathbf{3 . 2}$ & $3-5$ & 75 & 19.230 \\
$\mathbf{3 . 3}$ & $6-8$ & & \\
\hline
\end{tabular}

Table-3 Frequency and Percentage Distribution of Population according to the Persistence of Dysmenorrhoea for Three Consecutive or More Than Three Consecutive Menstrual Cycles, Number of Pads they Use in a Day and Day of Onset of Menstrual Pain. $\mathrm{N}=390$

\begin{tabular}{|c|c|c|}
\hline & Frequency & Percentage (\%) \\
\hline \multicolumn{3}{|c|}{$\begin{array}{l}\text { Dysmenorrhoea persisting for } 3 \text { consecutive or more than three consecutive } \\
\text { menstrual cycles }\end{array}$} \\
\hline Yes & 153 & 39.230 \\
\hline No & 237 & 60.769 \\
\hline \multicolumn{3}{|c|}{ No of pads per day during menstruation } \\
\hline $1-2$ & 264 & 67.692 \\
\hline $3-4$ & 121 & 31.025 \\
\hline $5-6$ & 5 & 1.282 \\
\hline \multicolumn{3}{|c|}{ Day of onset of menstrual pain } \\
\hline $1^{\text {st }}$ & 290 & 74.358 \\
\hline $2^{\text {nd }}$ & 56 & 14.358 \\
\hline $3^{\text {rd }}$ & 4 & 1.025 \\
\hline 1 day before & 6 & 1.538 \\
\hline 3-4 days before & 1 & 0.256 \\
\hline
\end{tabular}


Table-4 Frequency and Percentage Distribution of Population by the Site of Menstrual Pain.

\begin{tabular}{llll}
\multicolumn{2}{c}{$\mathbf{N = 3 9 0}$} & Percentage \\
\hline S.No. & Site of menstrual pain & Frequency & 49.230 \\
\hline $\mathbf{1}$ & Lower abdomen & 192 & 22.307 \\
$\mathbf{2}$ & Lower abdomen and back & 87 & 3.076 \\
$\mathbf{3}$ & Lower abdomen, back and thighs & 12 & 4.615 \\
$\mathbf{4}$ & Back & 18 & 0.256 \\
$\mathbf{5}$ & Knees & 1 & 0.256 \\
$\mathbf{6}$ & Lower abdomen and knees & 1 & 2.057 \\
$\mathbf{7}$ & Lower abdomen and legs & 8 & 2.820 \\
$\mathbf{8}$ & Lower abdomen back and legs & 11 & 0.769 \\
$\mathbf{9}$ & Back and legs & 3 & 0.769 \\
$\mathbf{1 0}$ & Thighs and legs & 3 & 3.589 \\
$\mathbf{1 1}$ & Lower abdomen and thigh & 14 & 0.512 \\
$\mathbf{1 2}$ & Thigh & 2 & 0.256 \\
$\mathbf{1 3}$ & Perineal area & 1 & 0.256 \\
$\mathbf{1 4}$ & Groin & 1 & 0.256 \\
$\mathbf{1 5}$ & Legs & 1 & 0.256 \\
$\mathbf{1 6}$ & Epigastric & 1 & 0.256 \\
$\mathbf{1 7}$ & Lower abdomen and body pain & 1 & \\
\hline
\end{tabular}

Table-5 Frequency And Percentage Distribution Of Population By The Duration Of Their Menstrual Pain, Treatment They Take For The Relief From Menstrual Pain And The Investigation They Have Undergone To Diagnose Problems Related To Menstruation. N=390

\begin{tabular}{llll}
\hline & & Frequency & Percentage \\
\hline $\mathbf{1}$ & Duration of menstrual pain (days) & 342 & 87.69 \\
$\mathbf{1 . 1}$ & $\mathbf{1 - 3}$ & 14 & 3.589 \\
$\mathbf{1 . 2}$ & $\mathbf{3 - 5}$ & 1 & 0.256 \\
$\mathbf{1 . 3}$ & $\mathbf{5 - 6}$ & & \\
$\mathbf{2}$ & Treatment taken for pain & 63 & 16.153 \\
$\mathbf{2 . 1}$ & Allopathic & 1 & 0.256 \\
$\mathbf{2 . 1}$ & Homeopathic & 3 & 0.769 \\
$\mathbf{2 . 3}$ & Ayurvedic & 2 & 0.512 \\
$\mathbf{2 . 4}$ & Yoga & 11 & 2.82 \\
$\mathbf{2 . 5}$ & Home remedies & & \\
$\mathbf{3}$ & Investigations & 21 & 5.384 \\
$\mathbf{3 . 1}$ & Yes (USG) & 369 & 94.165 \\
$\mathbf{3 . 2}$ & No & & \\
\hline
\end{tabular}

Table-6 Frequency and Percentage of Girls in Terms of Diagnostic Findings of Ultrasonography Which They Had Undergonend $=21$

\begin{tabular}{lll}
\hline Diagnostic findings of ultrasonography & Frequency & Percentage (\%) \\
\hline NAD & 18 & 4.615 \\
Cyst & 2 & 0.512 \\
Uterine fibroid & 1 & 0.256 \\
\hline
\end{tabular}

Table-7 Frequency And Percentage Distribution Of Population According To Their Inability To Attend College During Menstruation, Particular Diet Regimen Followed During Menstruation And The Information They Already Had About Pelvic Rocking Exercises N=390

\begin{tabular}{lll}
\hline & Frequency & Percentage \\
\hline Unable to attend college during menstruation & 39.230 \\
Yes & 153 & 54.102 \\
No & 211 & 6.660 \\
Sometimes & 26 & 7.435 \\
Particular diet regimen followed during menstruation & & 1.282 \\
More fluid & 29 & 1.794 \\
Avoid rice pickle and curd & 5 & 0.256 \\
Avoid oily and spicy food & 7 & 0.512 \\
Avoid ice cream and & 1 & 0.512 \\
Chocolates & 2 & 0.256 \\
More protein and iron & 2 & \\
Fruits & 1 & \\
\hline
\end{tabular}


Table -8 Frequency and Percentage Distribution of Population bythe Severity of Dysmenorrhoea

\begin{tabular}{lll} 
& \multicolumn{1}{c}{$\mathbf{N = 3 9 0}$} & \\
\hline Severity of dysmenorrhoea & Frequency & Percentage (\%) \\
\hline None & 33 & 8.461 \\
Mild & 77 & 19.473 \\
Moderate & 157 & 40.256 \\
Severe & 93 & 23.840 \\
Unbearable & 30 & 7.692 \\
\hline
\end{tabular}

Table-9 Percentage and Frequency Distribution of Demographic Characteristics of Girls n1+n2=60

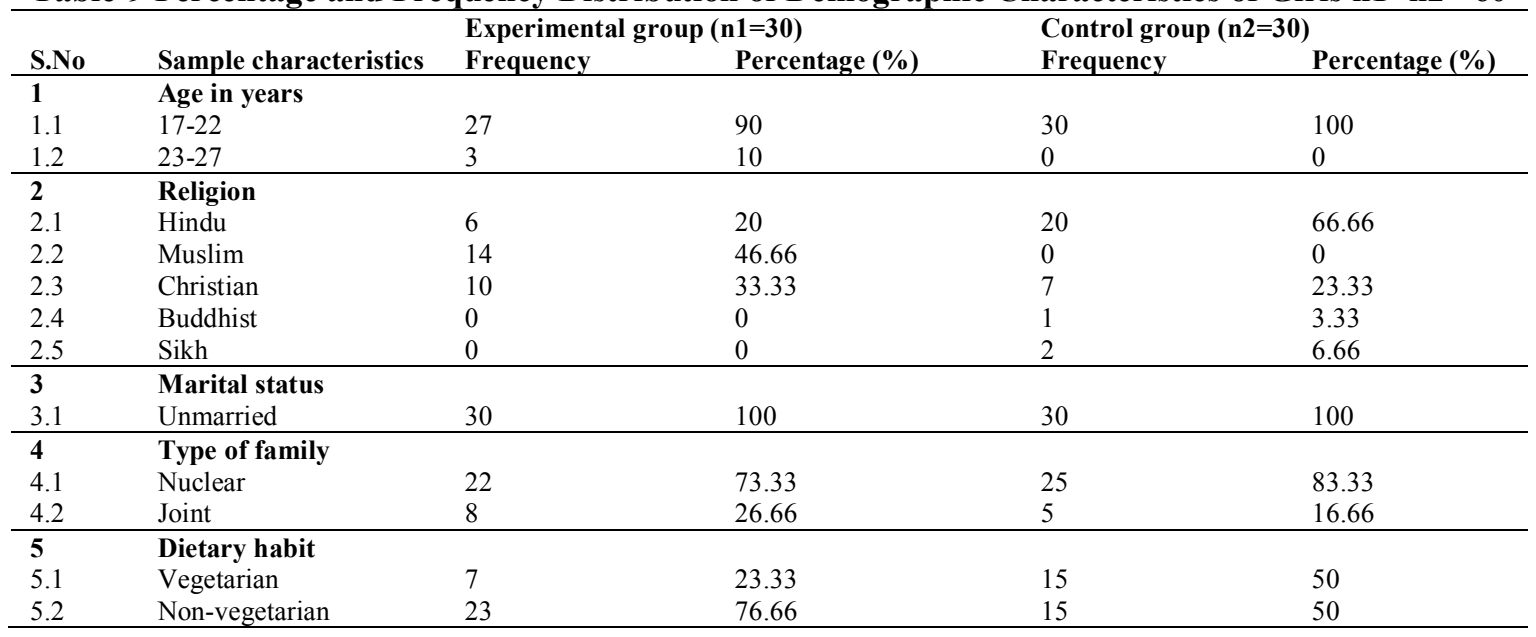

Table-10 Frequency and Percentage Distribution of Other Problems in Girls during Menstruation

\begin{tabular}{|c|c|c|c|}
\hline & Problems during menstruation & Frequency & Percentage \\
\hline 1 & Gastrointestinal symptoms & & \\
\hline 1.1 & Decreased appetite & 32 & 53.33 \\
\hline 1.2 & Nausea/vomiting & 22 & 36.66 \\
\hline 1.3 & Anorexia & 9 & 31.66 \\
\hline 1.4 & Gaseous distention of abdomen & 30 & 50 \\
\hline 2 & Psychological symptoms & & \\
\hline 2.1 & Depression easily & 23 & 38.33 \\
\hline 2.2 & Irritable & 43 & 71.66 \\
\hline 2.3 & Difficulty in concentrating on work & 45 & 75 \\
\hline 2.4 & Feel nervous & 16 & 26.66 \\
\hline 3 & Elimination symptoms & & \\
\hline 3.1 & Constipation & 15 & 25 \\
\hline 3.2 & Diarrhea & 10 & 16.66 \\
\hline 3.3 & Increased micturition & 15 & 25 \\
\hline 3.4 & Profuse sweating & 11 & 18.33 \\
\hline 4 & Other physical symptoms & & \\
\hline 4.1 & Feel lethargic & 40 & 66.66 \\
\hline 4.2 & Headache & 17 & 28.33 \\
\hline 4.3 & Sleeplessness & 25 & 41.66 \\
\hline 4.4 & More sleep & 18 & 30 \\
\hline 4.5 & Tenderness or fullness in breast & 22 & 36.33 \\
\hline 4.6 & Heaviness in lower abdomen & 42 & 70 \\
\hline 4.7 & Swelling in ankle or knee & 1 & 1.66 \\
\hline 4.8 & Backache & 47 & 78.33 \\
\hline
\end{tabular}

Psychological symptoms in girls during menstruation occur the most followed by gastrointestinal symptoms, other physical symptoms (which include headache, sleeplessness, more sleep, tenderness or fullness in breast, heaviness in lower abdomen, swelling in ankle or knee joint, backache and lethargic feeling) and elimination symptoms. 
A Randomized Control Trial To Assess And Evaluate The Effectiveness Of Pelvic Rocking ....

Table-11 Range, Mean, Median and Standard Deviation of Pre-Test and Post-Test Scores of Study Subjects in Experimental Group. n1=30

\begin{tabular}{llcccc}
\hline Pain score on VDS & Max Possible Score & Range of obtained score & Mean & $\begin{array}{c}\text { Median } \\
\text { Standard } \\
\text { deviation }\end{array}$ \\
\hline Pre-test & 5 & $3-5$ & 3.63333 & 3.5 & 0.7184 \\
Post-test & 5 & $3-5$ & 2.66667 & 2 & 0.99424 \\
\hline
\end{tabular}

\section{Data given in table-11 shows that:}

The mean post-test pain score (2.66667) is less than mean pre-test pain score (3.63333). There is increase in standard deviation from pre-test $(0.7184)$ to post-test $(0.99424)$. The mean and median are closer to each other in both pre-test and post-test. It is inferred that there is a marked reduction in pain of girls during menstruation.

\section{Discussion:}

Findings of the study revealed that very few girls were using Pelvic Rocking Exercises for the management of dysmenorrhoea. Findings of the study are found to be consistent with the study done by the Abbaspour Z.(2006) $)^{(9)}$. This study was a randomized clinical trial of 150 high school girl students in MasgedSolayman city suffering from severe dysmenorrhea. Students were separated in two "exercise "and "non exercise "groups. Then the "exercise "group was given some exercises and the results of the two periods after the exercise were registered. The descriptive statistics and repeated measure design were used for analyzing the statistical information. The results showed that the intensity of the pain in the exercise group declined from 8.59 to 4.63 in the third period and 2.84 in the fourth period $(\mathrm{P}<0.01)$. The average of using sedative tablets also decreased from 1.13 to 0.35 tablets in the third period and 0.0 tablets in the fourth period $(\mathrm{P}<0.01)$. This indicates that exercise can decrease the duration and severity of dysmenorrhea and also using of the sedative tablets in high school girls. Although in the present study the effect of pelvic Rocking Exercises were effective in reducing dysmenorrhoea.

\section{References}

[1]. Narayan KA et al. Puberty Rituals, Reproductive Knowledge and Health of Adolescent Schoolgirls in South India. Asia Pacific Population Journal. 2011; 16(2):224-236.

[2]. Jameison DJ, Steege JF. The prevalence of dysmenorrhea, dyspareunia, pelvic pain, and irritable bowel syndrome in primary care practices. Obstetrics \&Gynaecology. 1996 May; 87: 55-58.

[3]. Avasarala KA, Panchangam S. Dysmenorrhea in different settings: rural-urban. Indian Journal of community Medicine. 2008 Oct; 33(4): 246- 249 .

[4]. Balbach L. "What is aerobic exercise; and why I should do it?". Home and fitness. 2002; 5: 110-113.

[5]. Barnard N, Scialli A, Hurlock D. Diet and sex hormone binding globulin, dysmenorrhoea premenstrual symptoms. J. Obstet. 1986; 17(1):340-43.

[6]. Jones A. Managing the pain of primary and secondary dysmenorrhoea. Nursing Times Journal. 2004; 100(10):40-45.

[7]. Campbell O, Harlow S. Epidemiology of menstrual disorders in developing countries: A systematic review. British Journal of Obstetrics and Gynecology. 2004; 111:6-16.

[8]. Campbell MA, McGrath PJ. Non-pharmacological strategies used by adolescents for the management of menstrual discomfort. Clin J Pain. 1999; 15: 313-20.

[9]. Abbaspour Z, Najjar SH, Rostani M. The effect of exercise on primary dysmenorrhoea. J Res Health Sci. 2006; 6(1):26-31. 